\title{
Degradation of chlorophenol mixtures in a fed-batch system by two soil bacteria
}

\author{
Ignacio Durruty*, Elena Okada, Jorge F González and Silvia E Murialdo \\ Biochemical Engineering Group, Engineering School, National University of Mar del Plata, \\ Juan B. Justo 4302 CP. 7600 Mar del Plata, Argentina
}

\begin{abstract}
This work was undertaken to investigate the effect of variations of the feed rate on a fed-batch set-up used to degrade xenobiotics. The mixture of substrates was composed of PCP, 2,4,6 TCP and 2,3,5,6 TeCP (pentachlorophenol, 2,4,6 trichlorophenol and 2,3,5,6 tetrachlorophenol respectively). Two acclimated bacteria isolated from soil were used: Pseudomonas aeruginosa and Achromobacter sp. nov. The different flow rates tested were: I: $0.5 \mathrm{~m} \ell \cdot \mathrm{min}^{-1}$, II: $1.67 \mathrm{~m} \ell \cdot \mathrm{min}^{-1}$ and III: 2.00 $\mathrm{m} \ell \cdot \mathrm{min}^{-1}$. Our results show that during fed-batch operation the 2,4,6 TCP exhibits an earlier degradation than the other compounds, for all of the flow rates tested. This indicates that in this case the degradation of the most recalcitrant compounds ( $\mathrm{PCP}$ and 2,3,5,6 TeCP) is benefited by the increase in biomass of bacteria, due to the metabolisation of a less recalcitrant compound (2,4,6 TCP). The defined parameter, specific degradation rate (SDR), was demonstrated to be very useful for comparing the degradation abilities at different flow rates of a fed-batch system. The degradation efficiencies were shown to be higher than $90 \%$ for all of the cases and to decrease as the feed rate increases. However, the SDR, a parameter that involves the rate of degradation and the biomass, increases as the flow rate increases. At a feed flow rate of $2 \mathrm{~m} \ell \cdot \mathrm{min}^{-1} \mathrm{SDR}$ reaches a maximum of $12.476 \times 10^{-10} \mathrm{mgCP} \cdot \mathrm{h}^{-1} \cdot \mathrm{CFU}^{-1}$. Finally, among the feed flows tested, taking into account both the degradation efficiency and the SDR, $2 \mathrm{~m} \ell \cdot \mathrm{min}^{-1}$ is the most convenient flow rate for chlorophenol degradation in fed-batch systems. An even higher degradation efficiency (97\%) can be achieved by using the feed rate of $2 \mathrm{~m} \ell \cdot \mathrm{min}^{-1}$ followed by an additional batch post-treatment of $2 \mathrm{~h}$, with a SDR of $13.136 \times 10^{-10} \mathrm{mg} \mathrm{CP} \cdot \mathrm{h}^{-1} \mathrm{CFU}^{-1}$.
\end{abstract}

Keywords: Chlorophenol; fed batch system; aerobic degradation; waste treatment; microbial biocatalysis

\section{Introduction}

Microbial biodegradation processes in aerobic or anaerobic reactors are among the most widely used biological methods for removing chlorinated phenolic compounds $(\mathrm{CP})$ from contaminated waters. The exploration of new cultures capable of degrading xenobiotics without the addition of ancillary carbon sources is an approach that may result in significant cost reductions in the decontamination process. Field and Sierra-Alvarez (2008) have summarised a wide spectrum of strains of bacteria and fungi which are capable of using $\mathrm{CP}$ as the sole carbon and energy source.

While most researchers have studied biological treatment in batch reactors, several authors have proposed alternate configurations to improve the industrial application of CP degradation (Mun et al., 2008), including fed-batch reactor systems (Bali and Sengül, 2002; De Los Cobos-Vasconcelos et al., 2006). The fed-batch system allows for the treatment of larger quantities of wastewater than the batch system, with the same amount of initial inoculum (Blanch and Clark, 1996). In a typical fed-batch operation, wastewater is fed to the biological treatment unit either intermittently or continuously, usually at a low flow rate. Contrary to the continuous systems, the effluent is not withdrawn until the reactor is full. In this way, high concentrations of organic and toxic compounds are diluted in a large reaction volume, thus reducing inhibitory/toxic effects. As a result, biological oxidation of these compounds usually takes place at a higher rate (Bali and Sengül, 2002).

\footnotetext{
* To whom all correspondence should be addressed.

푱 +54 223 481-6600 Ext. 261; fax: +54 223 481-0046; e-mail: durruty@fi.mdp.edu.ar
}

Received 16 December 2010; accepted in revised form 5 September 2011.
In addition to their toxicity, CPs are the direct precursors of more dangerous compounds such as polychlorinated dibenzodioxins. CPs have been used extensively for the synthesis of many kinds of compounds such as pesticides, herbicides and dyes. Thus, CPs are found in various industrial and municipal wastes (Ozkaya, 2005; Majumder and Gupta, 2007; Tzou et al., 2008) and several wastewaters contain PCP, present in mixtures together with other CPs and aromatic compounds (Majumder and Gupta, 2007; Durruty et al., 2011). The degradation rate of one or more compounds may be altered when they occur within a mixture of toxic compounds: the rate may be stimulated, inhibited or decreased (Abuhamed et al., 2004; Baggi et al., 2004; Liu et al., 2006).

Since during simultaneous degradation the presence of other compounds can enhance or decrease the PCP degradation rate, it is important to know how the additional substrate may affect the overall degradation. Most CPs can be co-metabolised in the presence of an easily degradable carbon source (Kim and Hao, 1999; Wang and Loh, 2001; Tobajas et al., 2010). A possible strategy worth exploring is the use of lower chlorinated phenols in multi-substrate degradation to improve the overall degradation rate, instead of using easily degradable substrates. This is so because the use of readily-degradable ancillary carbon sources, such as glucose or amino acids, may favour the growth of tolerant but not CP-degrading microorganisms present in the CP-wastewater and which could compete with the degrading flora. The effect of a secondary chlorophenol on the removal of another chlorophenol present in the mixture has been investigated using batch (Yang et al., 2005; Tobajas et al., 2010) and fed-batch systems (Quan et al., 2005; De Los CobosVasconcelos et al., 2006). In previous work (Durruty et al., 2011), it has been demonstrated that the presence of 2,4,6-TCP 
Table 1

Initial experimental settings for the fed-batch assays at different feed flow rates (I, II, III) and for batch control (B)

\begin{tabular}{|c|c|c|c|c|c|c|c|c|}
\hline Assay & 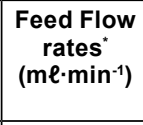 & $\begin{array}{c}\text { Initial PCP } \\
\text { Concentration } \\
\left(\mathbf{m g} \cdot \ell^{-1}\right)\end{array}$ & $\begin{array}{c}\text { Initial } \\
2,3,5,6 \mathrm{TeCP} \\
\text { Concentration } \\
\left(\mathrm{mg} \cdot \mathrm{\ell}^{-1}\right) \\
\end{array}$ & $\begin{array}{c}\text { Initial } 2,4,6 \text { TCP } \\
\text { Concentration } \\
\left(\mathrm{mg} \cdot \ell^{-1}\right)\end{array}$ & $\begin{array}{c}\text { Total Initial CP's } \\
\text { Concentration } \\
\left(\mathrm{mg} \cdot \mathrm{e}^{-1}\right)\end{array}$ & $\begin{array}{c}X_{0(V=0.5 \ell)} \\
\left(C F U \cdot \mathbf{C}^{-1}\right)\end{array}$ & $\begin{array}{c}X_{f(V=2 \ell)} \\
\left(C F U \cdot m \ell^{-1}\right)\end{array}$ & \begin{tabular}{|c|} 
Biomass yield \\
Coefficient \\
(CFU·mgCP-1)
\end{tabular} \\
\hline I & 0.50 & $2.344 \pm 0.121$ & $3.230 \pm 0.156$ & $3.793 \pm 0.187$ & $9.367 \pm 0.464$ & $\begin{array}{c}2.50 \times 10^{7} \pm \\
2.32 \times 10^{6}\end{array}$ & $\begin{array}{c}2.96 \times 10^{7} \pm \\
3.55 \times 10^{6}\end{array}$ & $\begin{array}{c}2.254 \times 10^{8} \pm \\
1.82 \times 10^{7}\end{array}$ \\
\hline II & 1.67 & $1.034 \pm 0.168$ & $0.542 \pm 0.117$ & $0.002 \pm 0.016$ & $1.576 \pm 0.302$ & $\begin{array}{c}2.81 \times 10^{7} \pm \\
3.09 \times 10^{6}\end{array}$ & $\begin{array}{c}3.11 \times 10^{7} \pm \\
2.65 \times 10^{6}\end{array}$ & $\begin{array}{c}2.368 \times 10^{8} \pm \\
2.01 \times 10^{7}\end{array}$ \\
\hline III & 2.00 & $2.691 \pm 0.136$ & $1.357 \pm 0.098$ & $1.004 \pm 0.103$ & $5.052 \pm 0.337$ & $\begin{array}{c}2.43 \times 10^{7} \pm \\
1.94 \times 10^{6}\end{array}$ & $\begin{array}{c}3.21 \times 10^{7} \pm \\
2.98 \times 10^{6}\end{array}$ & $\begin{array}{c}2.538 \times 10^{8} \pm \\
1.65 \times 10^{7}\end{array}$ \\
\hline B & 0 & $23.878 \pm 0.562$ & $21.532 \pm 0.434$ & $22.542 \pm 0.675$ & $67.952 \pm 1.671$ & $\begin{array}{l}2.32 \times 10^{7} \pm \\
2.08 \times 10^{6}\end{array}$ & $\begin{array}{c}3.95 \times 10^{7} \pm \\
3.11 \times 10^{6}\end{array}$ & $\begin{array}{c}2.398 \times 10^{8} \pm \\
1.43 \times 10^{7}\end{array}$ \\
\hline
\end{tabular}

* Feed concentration was $45 \mathrm{mg} \cdot \ell^{-1}$ of each $C P$ in all cases

(2,4,6 trichlorophenol) enhances the PCP degradation rate by the same culture in a binary mixture and in ternary mixture of 2,4,6TCP; 2,3,5,6 TeCP (2,3,5,6 tetrachlorophenol) and PCP. However, the biodegradation behaviour of the PCP, 2,4,6 $\mathrm{TCP}$ and 2,3,5,6 TeCP mixture in fed-batch systems remained unexplored. Therefore, this work was undertaken to study the multi-substrate degradation of PCP, 2,4,6 TCP and 2,3,5,6 $\mathrm{TeCP}$ in a fed-batch system, and the effect of different feed rates on system behaviour. These results add to the knowledge of fed-batch operations used to improve the degradation of mixtures of xenobiotics.

\section{Materials and methods}

\section{Microorganisms and culture conditions}

The mixed culture used in this work consisted of 2 strains isolated from soil contaminated with CP in the city of Mar del Plata: Pseudomonas aeruginosa (Murialdo et al., 2003) and Achromobacter marplatensis (Gomila et al., 2011) in a 1:1 ratio. They were isolated in the laboratory from soil contaminated with chlorophenols (Murialdo 2004; Wolski et al., 2006). These strains were selected for our research because they showed the best chlorophenol degradation kinetics among the isolated strains (Murialdo, 2004). In addition it has been shown that mixed cultures usually perform better than pure cultures (Sahinkaya and Dilek, 2007; Salmerón-Alcocer et al., 2007). A stock culture of bacteria was kept in liquid medium prior to its use in the experiments. The medium (MS) contained the following inorganic salts $\left(\mathrm{g} \cdot \ell^{-1}\right): \mathrm{PO}_{4} \mathrm{~K}_{2} \mathrm{H}(0.65) ; \mathrm{PO}_{4} \mathrm{H}_{2} \mathrm{~K}(0.17) ; \mathrm{NH}_{4} \mathrm{CL}_{5}(0.05) ; \mathrm{NaNO}_{3}$, (0.05); $\mathrm{MgSO}_{4} 7 \mathrm{H}_{2} \mathrm{O}(0.1)$, and a mixture of PCP $\left(20 \mathrm{mg} \cdot \ell^{-1}\right)$, $2,4,6 \mathrm{TCP}\left(20 \mathrm{mg} \cdot \ell^{-1}\right)$ and $2,3,5,6 \mathrm{TecP}\left(20 \mathrm{mg} \cdot \ell^{-1}\right)$ as the only source of carbon and energy. Before inoculations, all media were adjusted to $\mathrm{pH} 7$ and autoclaved at $121^{\circ} \mathrm{C}$ for $15 \mathrm{~min}$. The bacteria were acclimated as described in Durruty et al. (2011).

\section{Analytical methods}

The bacterial population was estimated by the plate count method at the beginning and at the end of every run. The concentration of $\mathrm{CP}$ was measured using high performance liquid chromatography (HPLC) equipped with a Waters Division of Millipore Model 590 pump, a Waters Division of Millipore Model 484 UV detector and a Waters Spherisorb $5 \mu \mathrm{m}$ oOD52 4.6 x $250 \mathrm{~mm}$ Analytical Column (Millipore Corporation, Milford, Massachusetts). The UV detector was set at $219 \mathrm{~nm}$. The mobile phase was acetonitrile and $7 \mathrm{mM}$ phosphoric acid $(70: 30, \mathrm{v} / \mathrm{v})$ with a flow rate of $1 \mathrm{~m} \ell \cdot \mathrm{min}^{-1}$.

\section{Fed-batch system}

The bioreactor used for fed-batch experiments was a $2.0 \ell$ stirred vessel made of Pyrex glass (Omni-Culture, Virtis Co., Gardiner, N.Y.) with an aeration system. Air was supplied through a Balston DFU grade AQ filter at $1 \ell \cdot \mathrm{min}^{-1}$ through a deep tube located at the bottom of the vessel close to the lower turbine. The temperature was maintained at $25^{\circ} \mathrm{C}$ in a temperature-controlled room. The reactor was operated initially as a $0.5 \ell$ batch with an initial inoculum of $10 \% \mathrm{v} / \mathrm{v}$ of the stock culture with a medium composed of mineral salts (MS) and a mixture of $20 \mathrm{mg} \cdot \ell^{-1}$ of each chlorophenol (2,4,6 TCP, 2,3,5,6 TeCP and PCP) as sole carbon and energy source, with the aim to enrich the culture. When $\mathrm{CP}$ concentrations are close to zero (the values are shown in Table 1), a sterile medium with a mixture of $45 \mathrm{mg} \cdot \ell^{-1}$ of each one of the 3 CPs and MS was supplied, and thus fedbatch operation was started $(t=0 \mathrm{~h})$. The sterile medium was supplied through a Gilson pump (Model 302) with an inlet constant flow rate $(\mathrm{F})$. Three different assays were planned to evaluate the feed-rate effect on system performance. The different flows tested were: I: $0.5 \mathrm{~m} \ell \cdot \mathrm{min}^{-1}$, II: $1.67 \mathrm{~m} \ell \cdot \mathrm{min}^{-1}$ and III: $2.00 \mathrm{~m} \ell \cdot \mathrm{min}^{-1}$. The initial volume was $0.5 \ell$ in all cases and the medium was pumped into the reactor until a final volume of $2 \ell$ was reached. Samples were drawn at different time intervals to measure the concentration of each CP. The biomass was quantified at the beginning and at the end of the fed-batch operation.

\section{Batch control assay}

For comparison purposes, a batch system process was carried out simultaneously as a control, using the same inoculum as in the fed-batch experiment. The test was conducted in $250 \mathrm{~m} \ell$ Erlenmeyer flasks containing $0.15 \ell$ of the MS and PCP, TCP and $\mathrm{TeCP}$ as the only source of carbon and energy. The batch control reactor was inoculated with the enriched liquid from the fed-batch reactor at $t=0 \mathrm{~h}$. Initial $\mathrm{CP}$ and biomass concentrations are shown in Table 1. The cultures were incubated in a dark room, at $25^{\circ} \mathrm{C}$ with constant agitation $\left(120 \mathrm{r} \cdot \mathrm{min}^{-1}\right)$ in an orbital shaker (Shaker Pro, Vicking Co. Buenos Aires, Argentina).

\section{Theoretical accumulation considering a zero compound removal $\left(C_{i}\right)$}

The global accumulation rate of substrate $i$ of concentration $\left(S_{i}\right)$ in a fed-batch reactor is expressed as: 
$\left[\frac{d V \cdot S_{i}}{d t}\right]_{a c c}=V \cdot\left[\frac{d S_{i}}{d t}\right]+S_{i} \cdot\left[\frac{d V}{d t}\right]=F \cdot S_{i f}-\left[\frac{d V . S_{i}}{d t}\right]_{\mathrm{deg}}$

where:

$t$ is the operation time

$V$ is the actual volume of reactor

$S_{i}$ is the concentration of substrate $i$

$F$ is the constant inlet flow rate

$S_{i f}$ is the concentration of the compound $i$ in the inlet

The first term ([dVS/dt $\left.]_{\text {acc }}\right)$ represents the net accumulation of the component $i$ in the control volume $V$, while $F \cdot S_{i f}$ represents the input of compound $i$ to the volume control, and the last term $\left([d V S / d t]_{\operatorname{deg}}\right)$ represents the actual degradation rate. Note that the control volume $V$ is not constant since the volume $V$ increases at a rate $d V / d t$, which is equal to $F$. Therefore, $V(t)=V_{0}+F \cdot t$.

In absence of degradation $\left([d V S / d t]_{\mathrm{deg}}=0\right)$, this equation describes the accumulation of the substrate $i$ in the system. Hence, the mass balance results:

$$
\left(V_{0}+F . t\right) \cdot\left[\frac{d S_{i}}{d t}\right]+S_{i} \cdot F=F . S_{i f}
$$

Solving the balance equation (Eq. (2)) with the initial conditions of the fed-batch process at $t_{0}=0$, initial concentration of the CP $i\left(S_{i(t=0)}\right)$, and solving for $S_{i}$, yields the theoretical accumulation of a substrate $i$ when the degradation rate is zero $\left(C_{i}\right)$ in the fed-batch reactor (Eq. (3)), as presented by De Los Cobos Vasconcellos et al. (2006):

$$
\begin{aligned}
C_{i} & =S_{i f}-\frac{\left(S_{i f}-S_{i(t=0)}\right) \cdot V_{0}}{V_{0}+F \cdot t}=\frac{S_{i f} \cdot F \cdot t+V_{0} \cdot S_{i(t=0)}}{V_{0}+F . t} \\
& =\frac{m_{\text {feed }}(t)+m_{i}}{V(t)}
\end{aligned}
$$

Note that in Eq. (3) $C_{i}$ represents the cumulative mass of the $i$ compound added to the actual volume at each time.

\section{Specific degradation rate parameter (SDR)}

A comparison of the batch and fed-batch systems by merely looking at the concentration in the reactor or the degradation efficiency is not adequate, due to the different feed strategies. Initially, a parameter that involves the total mass of substrates in the system is necessary. Thus, to compare the effectiveness of the different strategies used to degrade, the specific degradation rate (SDR) was defined as the total mass of compound $i$ degraded per unit of time and initial biomass. For the fed-batch system, the SDR results:

$$
S D R_{i}=\frac{S_{i f} \cdot F \cdot t+V_{(t=0)} \cdot S_{i(t=0)}-V_{(t)} \cdot S_{i(t)}}{t \cdot X_{(t=0)} \cdot V_{(t=0)}}
$$

and the SDR parameter for the batch system, when $F=0$, is:

$$
S D R_{i}=\frac{V_{(t=0)} \cdot S_{i(t=0)}-V_{(t)} \cdot S_{i(t)}}{t \cdot X_{(t=0)} \cdot V_{(t=0)}}=\frac{S_{i(t=0)}-S_{i(t)}}{t \cdot X_{(t=0)}}
$$

This parameter is a very useful tool that involves the degradation rate and the biomass growth, referred to the initial biomass instead of the actual biomass. Progressively, the biomass grows and the degradation rate increases. This parameter simultaneously takes both into account.

\section{Results and discussion}

The mixed culture constituted of Pseudomonas aeruginosa and Achromobacter marplatensis was able to simultaneously degrade the mixture of highly-substituted chlorophenols PCP, 2,3,5,6-TeCP and 2,4,6-TCP, as the only source of carbon and energy in batch and fed-batch systems. The initial experimental settings for the fed-batch assays at different feed flow rates (I, II, III) and the batch system control (B) is shown in Table 1. The initial biomass was similar in all cases but the initial CP concentrations were much higher in $\mathrm{B}$ than in the fed-batch assays when they were close to zero (Table I). The substrate to biomass yield coefficients based on total CP degradation are also shown in Table 1. These values are higher than those previously reported by Durruty et al. (2011) for the same strain and acclimated condition, exposed to similar CP concentrations but with lower biomass concentration. These results support the observation of Moreno-Andrade and Buitrón (2003), who observed that growth inhibition is not only a function of the initial substrate concentration, but also of the initial biomass concentration. This is due to the fact that the concentration of toxic compounds to which the biomass is exposed is lower per unit of biomass, thus the toxic effects are reduced.

The actual concentration of different CPs in the 3 fed-batch assays during the first $10 \mathrm{~h}$, and the total amount of substrate added $\left(C_{i}\right)$ for each, calculated with Eq. (3), are shown in Fig. 1. The degraded CP concentration is represented by the difference between $C_{i}$ and the measured $\mathrm{CP}$ concentration. The degradation rate is represented by the difference between the first derivative of the accumulation (the slope of the curve $C$ vs. $t$ represents the accumulation rate) and the first derivative of the actual concentration (slope of the curve $S_{i}$ vs. $t$ represents the net degradation rate). Therefore, the difference between the slopes of the curves is proportional to the degradation rate. In Assay I, the degradation rate was higher than the accumulation rate for all of the CPs (Figs.1, Ia, Ib and Ic), and the concentration diminishes from the start (negative net rate). In conclusion, the feed limited the degradation rate during Assay I. In Assays II and III the compounds accumulated initially because the degradation rate was slower than the accumulation rate (positive net rate). Later, when the increase in biomass causes an increment in the degradation rate, it exceeds the accumulation rate (negative net rate) and the $\mathrm{CP}$ concentration decreases. In the case of PCP, degradation was slower than for the rest of the CPs. This was evident in Assay III (Fig.1, IIIa) when the accumulation rate is the highest. The actual concentration of PCP increased proportionally with the increase in volume of the reactor, close to the theoretical accumulation. This indicates a low degradation rate. After $5 \mathrm{~h}$ it began to degrade faster, due to the increase in biomass. The low accumulation of 2,4,6 TCP during Assays II and III (Figs.1, IIc and Figs.1, IIIc, respectively) indicates that the bacteria consume this compound as it enters the reactor. The 2,3,5,6 TeCP degradation followed a similar trend to that of the PCP degradation: it was accumulated during Assay III until Day 5 (Figs.1, IIIb); both presented a minor accumulation in Assay II until Day 3 (Figs.1, IIa for PCP and Figs. 1, IIb for 2,3,5,6TeCP). In all of the cases the concentration of 2,4,6 TCP reaches its maximum before that of the other compounds, indicating an earlier degradation of this compound. The fact that this maximum is also lower than the other 2 maxima indicates that the 2,4,6 TCP degradation is faster. This suggests that in this case the degradation of the most recalcitrant compounds (PCP and 2,3,5,6 TeCP) is benefited by the increase in biomass of bacteria, due to the 


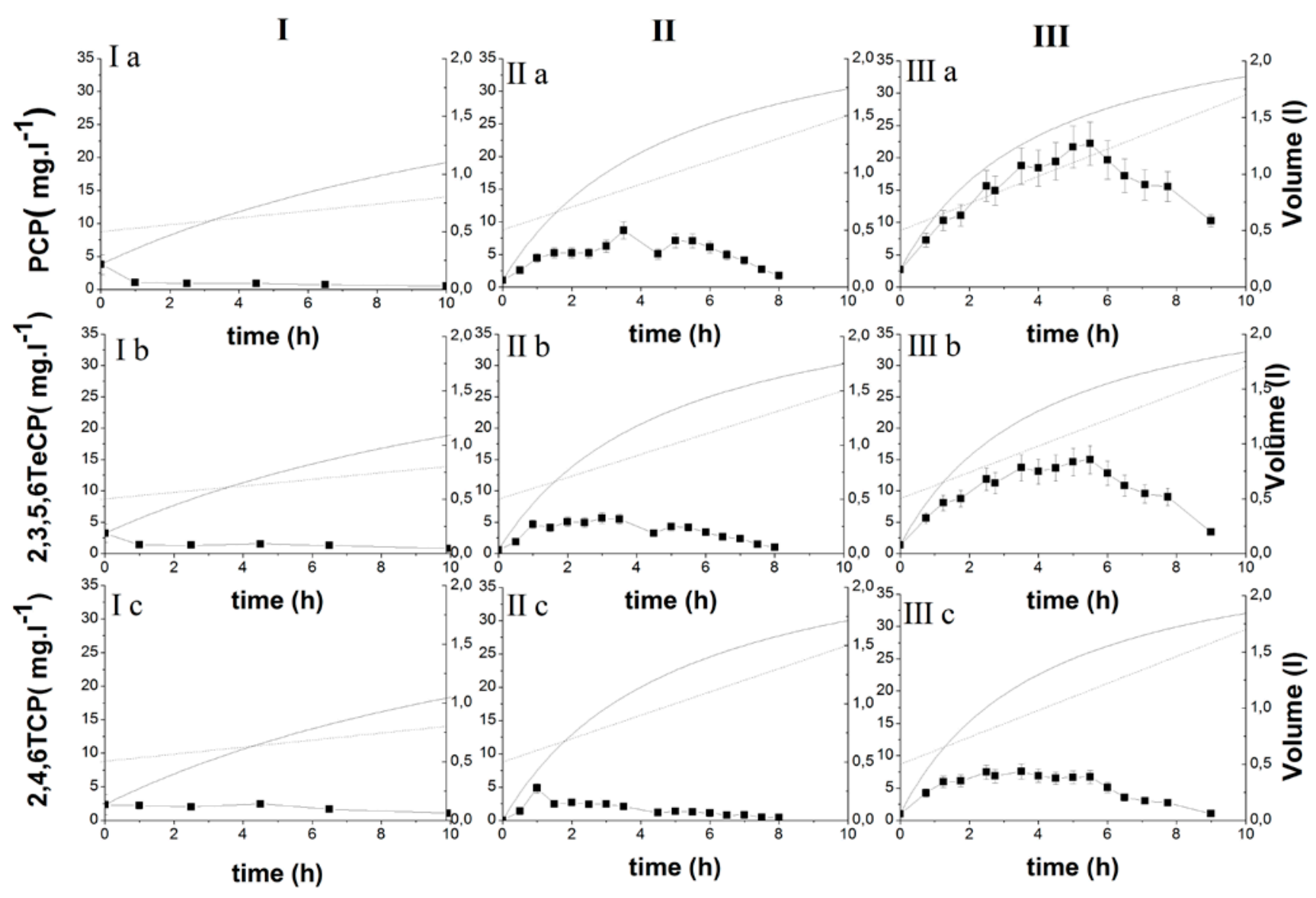

Figure 1

Transient accumulation of every CP in fed-batch system fed with MS containing $45 \mathrm{mg} \cdot \ell^{-1}$ of each CP. The columns represent different assays with a feed flow of I: $0.5 \mathrm{ml} \cdot \mathrm{min}^{-1}$; II: $1.67 \mathrm{ml} \cdot \mathrm{min}^{-1}$, III: $2 \mathrm{ml} \cdot \mathrm{min}^{-1}$. The rows represent the actual concentrations of each CP (ロ): (a) PCP, (b) 2,3,5,6TeCP and (c) 2,4,6TCP.

The total cumulative concentration of substrate added calculated with Eq. (3), considering a zero compound removal rate (solid line) and the total volume in the reactor (dashed line), is also shown for each test.

metabolisation of a less recalcitrant compound $(2,4,6 \mathrm{TCP})$ (Guha et al., 1999; Durruty et al., 2011). This agrees with the results of Quan et al. (2005), who found that in the fed-batch system with mixed components, 2,4DCP (less recalcitrant) was always degraded first; when it reached near-complete removal, the degradation of $4 \mathrm{CP}$ (more recalcitrant) started to take place.

The final values of specific degradation rate (SDR) for the fed-batch assays at different feed flows (I, II, III), calculated with Eq. (4), and for batch control (B), calculated with Eq. (5), are shown in Table 2. The values of the operating time (h), feed $\mathrm{CP}$ concentration $\left(\mathrm{mg} \cdot \ell^{-1}\right)$ and maximum $\mathrm{CP}$ concentration $\left(\mathrm{mg} \cdot \ell^{-1}\right)$ reached during the test for each assay are also shown in Table 2. In Assay I, although the amount of degraded CP is greater than in the batch test, the time necessary to process the CP makes the SDR lower due to the low feed flow, and limits the net degradation rate.

The CPs are highly toxic and usually exhibit substrate inhibition (Kargi et al., 2005; Chen and Lin, 2006; Konya et al., 2007), although the concentration at which the compound starts to inhibit depends strongly on the strain and the acclimation procedure (Moreno-Andrade and Buitrón, 2004; Sahinkaya and Dilek, 2005). For the culture used in this work, under the conditions described above, the onset of inhibition in PCP degradation was observed from 40 to $50 \mathrm{mg} \cdot \ell^{-1}$ of PCP (data not shown) and the degradation did not take place at initial concentrations above $150 \mathrm{mg} \cdot \ell^{-1}$. This suggests that the values of total $\mathrm{CP}$ concentration must be maintained below $50 \mathrm{mg} \cdot \ell^{-1}$ to avoid a detrimental effect on total CP degradation. Thus, the marked increase in the SDR obtained in Assay II and III is attributed to the feeding strategy, which allows lower levels of toxic compounds to be maintained in the fed-batch reactor in spite of the fact that the concentration of the toxic compound in the feed $\left(135 \mathrm{mg} \cdot \ell^{-1}\right)$ is higher than that which the culture is able to withstand. (Blanch and Clark, 1996; De Los Cobos-Vasconcelos et al., 2006). In our experiments, even though the feed concentration was more than twice as high as that to which the bacteria were acclimated, the maximum CP concentration in the reactor (that to which the bacteria are actually exposed) (Table 2) never exceeds the acclimation concentration. Therefore, the detrimental effects of substrate inhibition on CP degradation are avoided. These results agree with those of Bali and Sengül (2002), who concluded that the feeding strategy is a key factor for complete removal of both growth and non-growth substrates in fed-batch operation with no acclimated bacteria.

The degradation efficiency, measured as the ratio between the total degraded substrate and the total fed substrate, is shown in Table 2 for each test done. In all cases degradation efficiency was higher than $90 \%$ and decreased as the feed flow 


\section{Table 2}

Final values of specific degradation rate (SDR) for fed-batch assay at different feed flows (I, II, III), calculated with Eq. (4), and for batch control (B), calculated with Eq. (5). Operation time (h), feed CP concentration (mg $\cdot \ell^{-1}$ ) and maximum CP concentration reached during the test $\left(\mathrm{mg} \cdot \mathrm{l}^{-1}\right)$ for each assay.

\begin{tabular}{|c|c|c|c|c|c|c|c|c|}
\hline & \multicolumn{4}{|c|}{ 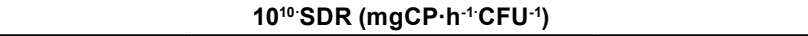 } & \multirow{2}{*}{$\begin{array}{l}\text { Feed CP } \\
\text { concen- } \\
\text { tration } \\
\left(\mathrm{mg} \cdot \ell^{-1}\right)\end{array}$} & \multirow{2}{*}{$\begin{array}{c}\text { Max. CP } \\
\text { concentration } \\
\left(\mathrm{mg} \cdot \ell^{-1}\right)\end{array}$} & \multirow{2}{*}{$\begin{array}{c}\text { Operation } \\
\text { time (h) }\end{array}$} & \multirow{2}{*}{$\begin{array}{c}\text { Degradation } \\
\text { efficiency }\end{array}$} \\
\hline Assay & PCP & $2,3,5,6 \mathrm{TeCP}$ & $2,4,6$ TCP & Total CPs & & & & \\
\hline I & $1.110 \pm 0.118$ & $1.106 \pm 0.183$ & $1.099 \pm 0.017$ & $3.315 \pm 0.318$ & $135^{*}$ & $9.367 \pm 0.912$ & 50 & $98 \%$ \\
\hline II & $3.233 \pm 0.236$ & $3.222 \pm 0.071$ & $3.209 \pm 0.158$ & $9.664 \pm 0.465$ & $135^{*}$ & $16.251 \pm 0.867$ & 15.6 & $97 \%$ \\
\hline III & $3.718 \pm 0.186$ & $4.369 \pm 0.218$ & $4.381 \pm 0.219$ & $12.476 \pm 0.623$ & $135^{*}$ & $40.041 \pm 2.743$ & 12.5 & $90 \%$ \\
\hline B & $1.239 \pm 0.106$ & $1.137 \pm 0.154$ & $1.214 \pm 0.087$ & $3.591 \pm 0.347$ & - & $67.952 \pm 1.671$ & 8 & $98 \%$ \\
\hline
\end{tabular}

*45 $\mathrm{mg} \cdot \ell^{-1}$ of each $C P$

increased. These results are similar to those found by De Los Cobos-Vasconcelos et al. (2006), who reported degradation efficiencies between 93 and $100 \%$ in the fed-batch reactor during the simultaneous degradation of mono- and dichlorophenols by a strain of Burkholderia.

On the other hand, in the range of feed rates evaluated, the SDR, which involves degradation rate and biomass requirements, increases with higher feed flow rates. But, as the feeding rate increases the concentrations begin to approach the values to which the bacteria are acclimated (Table 2). Tests at higher feed flow rates must be performed to confirm this tendency, although, based on the results obtained in this work, it is expected that a very high feeding rate could lead to an excessive accumulation of toxics compounds, which will have deleterious effects on the degradation efficiency and even prevent degradation.

In summary, during Assay III, at a feed flow rate of $2 \mathrm{~m} \ell \cdot \mathrm{min}^{-1}$, the SDR reaches a maximum of $12.476 \times 10^{-10}$ $\mathrm{mgCP} \cdot \mathrm{h}^{-1} \cdot \mathrm{CFU}^{-1}$; however, the lowest degradation efficiency is achieved. This results because at the time that the maximum working volume within the reactor was reached, some accumulated CPs still remained inside it. Nevertheless, an additional batch time of $2 \mathrm{~h}$ is sufficient to reach a degradation efficiency higher than $97 \%$. Application of Assay III plus this additional batch post-treatment resulted in an SDR of $13.136 \times 10^{-10}$ $\mathrm{mgCP} \cdot \mathrm{h}^{-1} \cdot \mathrm{CFU}^{-1}$. Thus, a flow rate of $2 \mathrm{~m} \ell \cdot \mathrm{min}^{-1}$ demonstrated better degradation abilities for a mixture of $\mathrm{CP}$ than lower feed flow rates and than a batch process.

Figure 2 shows the evolution of the SDR for different CPs in Assay III. The SDR for 2,4,6 TCP and 2,3,5,6 TeCP increases as the dilution rate (D) decreases (Fig. 2). This demonstrates that, once the operating conditions are chosen, with longer operating times (larger final volumes) the degradation ability increases. The SDR for PCP, however, deteriorates initially due to the slower degradation rates (as discussed above). After $5 \mathrm{~h}$, when the total degradation rate is higher than the accumulation rate due to the lower dilution rate, the SDR for PCP begins to increase. In this case, an operating time lower than $6 \mathrm{~h}$ will be sub-optimal for degradation of most recalcitrant compounds.

The results obtained in this work indicate that the selection of a reaction system in combination with its operating conditions is a key factor for the improvement of toxic-substrate biodegradation rates. Further insight into the degradation process could be gained by varying the initial concentrations and the operating temperature.

\section{Conclusions}

The mixed culture constituted by Pseudomonas aeruginosa and Achromobacter sp. was able to simultaneously degrade

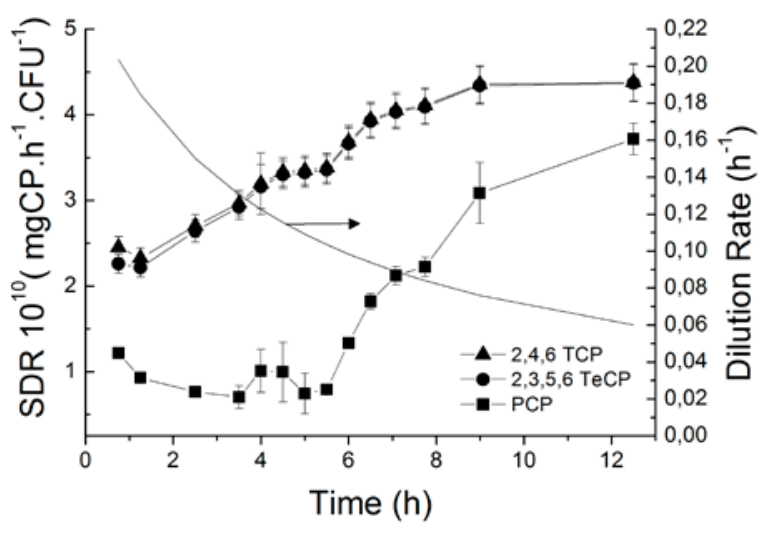

Figure 2

Evolution over time of SDR for different CPs in Assay III. The dilution rate (solid line) is shown on the right $y$-axis.

the mixture of highly-substituted chlorophenols, PCP, 2,3,5,6-TeCP and 2,4,6-TCP, as the only source of carbon and energy in batch and fed-batch systems. During fed-batch operation the 2,4,6 TCP exhibits an earlier degradation than the other compounds, for all of the processes applied. This indicates that in this case the degradation of the most recalcitrant compounds (PCP and 2,3,5,6TeCP) is benefited by the increase in biomass of bacteria, due to the metabolisation of a compound less recalcitrant $(2,4,6 \mathrm{TCP})$. The defined parameter, SDR, was demonstrated to be very useful for comparing the degradation abilities at different flow rates for a fed-batch system. The degradation efficiencies were higher than $90 \%$ in all of the cases and decreased as feed flow increased. However, the SDR, which involves both degradation rate and biomass requirements, increases as flow rate increases. Finally, among the feed flows tested, taking into account both the degradation efficiency and the SDR, 2 $\mathrm{m} \ell \cdot \mathrm{min}^{-1}$ was found to be the most convenient for CP degradation in fed-batch systems. An even higher degradation efficiency, of $97 \%$, and a higher SDR, can be achieved using a feed rate of $2 \mathrm{~m} \ell \cdot \mathrm{min}^{-1}$ which is followed by an additional batch post-treatment of $2 \mathrm{~h}$.

\section{Acknowledgements}

Support was provided by grants from the National University of Mar del Plata (15/G247) and the ANPCyT of Argentina (PICT N 00556). I. Durruty holds a fellowship from CONICET. E. Okada acknowledges the CIC for a fellowship received. S. Murialdo is a staff researcher of CIC (Province of Buenos Aires). 


\section{References}

ABUHAMED T, BAYRAKTAR E, MEHMETOGLU T and MEHMETOGLU U (2004) Kinetics model for growth of Pseudomonas putida $\mathrm{F} 1$ during benzene, toluene and phenol biodegradation. Process Biochem. 39 983-988.

BAGGI G, CAVALCA L, FRANCIA P and ZANGROSSI M (2004) Chlorophenol removal from soil suspensions: Effects of a specialised microbial inoculum and a degradable analogue. Biodegradation 15 (3) 153-160.

BALI U and SENGÜL F (2002) Performance of a fed-batch reactor treating a wastewater containing 4-chlorophenol. Process Biochem. (Amsterdam, Neth.) 37 (11) 1317-1323.

BLANCH HW and CLARK DS (1996) Biochemical Engineering. Marcel Dekker Inc., New York.

CHEN C-Y and LIN J-H (2006) Toxicity of chlorophenols to Pseudokirchneriella subcapitata under air-tight test environment Chemosphere 62 (4) 503-509.

DE LOS COBOS-VASCONCELOS D, SANTOYO-TEPOLE F, JUÁREZ-RAMÍREZ C, RUIZ-ORDAZ N and GALÍNDEZMAYER CJJ (2006) Cometabolic degradation of chlorophenols by a strain of Burkholderia in fed-batch culture. Enzyme Microb. Technol. 40 (1) 57-60.

DURRUTY I, OKADA E, GONZÁLEZ JF and MURIALDO SE (2011) Multisubstrate Monod kinetic model in simultaneous degradation of chlorophenols mixture. Biotechnol. Bioprocess Eng. 16 (5) 908-915.

FIELD J and SIERRA-ALVAREZ R (2008) Microbial degradation of chlorinated phenols. Rev. Environ. Sci, Biotechnol. 7 (3) 211-241.

GOMILA M, TVRZOVÁ L, TESHIM A, SEDLÁČEK I, GONZÁLEZ-ESCALONA N, ZDRÁHAL Z, ŠEDO O, GONZÁLEZ JF, BENNASAR A, MOORE ERB, LALUCAT J and MURIALDO SE (2011) Achromobacter marplatensis sp. nov., isolated from a pentachlorophenol contaminated soil. Int. J. System. Evol. Microb. $612231-2237$.

GUHA S, PETERS CA and JAFFE PR (1999) Multisubstrate biodegradation kinetics of naphthalene, phenanthrene, and pyrene mixtures. Biotechnol. Bioeng. 65 (5) 491-499.

KARGI F, UYGUR A and BASKAYA HS (2005) para-Chlorophenol inhibition on COD, nitrogen and phosphate removal from synthetic wastewater in a sequencing batch reactor. Bioresour. Technol. 96 (15) 1696-1702.

KIM MH and HAO OJ (1999) Co-metabolic degradation of chlorophenols by Acinetobacter species. Water Res. 33 562-574

KONYA I, EKER S and KARGI F (2007) Mathematical modelling of 4-chlorophenol inhibition on COD and 4-chlorophenol removals in an activated sludge unit. J. Hazard. Mater. 143 (1-2) 233-239.

LIU D, MAGUIRE RJ, PACEPAVICIUS G and DUTKA BJ (2006) Biodegradation of recalcitrant chlorophenols by cometabolism. Environ. Toxicol. Water Qual. 6 (1) 85-95.

MAJUMDER PS and GUPTA SK (2007) Removal of chlorophenols in sequential anaerobic-aerobic reactors. Bioresour. Technol. 98 (1) $118-129$.
MORENO-ANDRADE I and BUITRÓN G (2003) Influence of the initial substrate to microorganisms concentration ratio on the methanogenic inhibition. Water Sci. Technol. 48 (6) 17-22.

MORENO-ANDRADE I and BUITRÓN G (2004) Variation of the microbial activity during the acclimation phase of a SBR system degrading 4-chlorophenol. Water Sci. Technol. 50 (10) 251-258.

MUN CH, NG WJ and HE J (2008) Acidogenic sequencing batch reactor start-up procedures for induction of 2,4,6-trichlorophenol dechlorination. Water Res. 42 (6-7) 1675-1683.

MURIALDO SE (2004) Isolation and characterization of chlorophenol degrading microorganisms. Ph. D. thesis, National University of Mar del Plata.

MURIALDO SE, HAURE PM, FENOGLIO MR and GONZALEZ JF (2003) Degradation of phenol and chlorophenols by mixed and pure cultures. Water SA 29 (4) 457-463.

OZKAYA B (2005) Chlorophenols in leachates originating from different landfills and aerobic composting plants. J. Hazard. Mater. 124 (1-3) 107-112.

QUAN X, YANG Z, SHI H, TANG Q and QIAN Y (2005) The effect of a secondary chlorophenol presence on the removal of 2,4-dichlorophenol $(2,4-\mathrm{DCP})$ in an activated sludge system bioaugmented with 2,4-DCP degrading special culture. Process Biochem. 40 3462-3467.

SAHINKAYA E and DILEK FB (2005) Biodegradation of 4-chlorophenol by acclimated and unacclimated activated sludge Evaluation of biokinetic coefficients. Environ. Res. 99 (2) 243-252.

SAHINKAYA E and DILEK FB (2007) Biodegradation kinetics of 2,4-dichlorophenol by acclimated mixed cultures. J. Biotechnol. 127 (4) 716-726.

SALMERÓN-ALCOCER A, RUIZ-ORDAZ N, JUÁREZ-RAMÍREZ C and GALÍNDEZ-MAYER J (2007) Continuous biodegradation of single and mixed chlorophenols by a mixed microbial culture constituted by Burkholderia sp., Microbacterium phyllospharaeae and Candida tropicalis. Biochem. Eng. J. 37 201-211.

TOBAJAS M, MONSALVO VM, MOHEDANO AF and RODRIGUEZ JJ (2010) Enhancement of cometabolic biodegradation of 4-chlorophenol induced with phenol and glucose as carbon sources by Comamonas testosteroni J. Enviro. Manage. doi:10.1016/j. jenvman.2010.09.030.

TZOU Y-M, WANG S-L, LIU J-C, HUANG Y-Y and CHEN J-H (2008) Removal of 2,4,6-trichlorophenol from a solution by humic acids repeatedly extracted from a peat soil. J. Hazard. Mater. 152 (2) 812-819.

WANG SJ and LOH KC (2001) Biotransformation kinetics of Pseudomonas putida for cometabolism of phenol and 4-chlorophenol in the presence of sodium glutamate. Biodegradation 12 189-199.

WOLSKI EA, MURIALDO SE and GONZALEZ JF (2006) Effect of $\mathrm{pH}$ and inoculum size on pentachlorophenol degradation by Pseudomonas sp. Water SA 32 93-98.

YANG C-F, LEE C-M and WANG C-C (2005) Degradation of chlorophenols using pentachlorophenol-degrading bacteria Sphingomonas chlorophenolica in a batch reactor. Curr. Microbiol. 51 156-160. 